\title{
A penny for your thoughts
}

\section{Even a small effort can have a big impact on science education in Africa. Why don't you try?}

It is hardly necessary to emphasize the need to end the widespread poverty on the African continent. The images of hunger, war and ecological devastation are all too present in our minds. However, our efforts to solve the global poverty crisis remain inadequate, as even decades of foreign help have not significantly improved the situation in the most impoverished regions of Central Africa. Moreover, global warming is predicted to hit hardest those who least contribute to the increase in carbon dioxide emissions - those in arid areas of Africa who already have to fight off draughts and famine.

Unfortunately, some past initiatives to improve the situation have been counterproductive and have only increased the dependence on foreign aid. For example, current US law forbids the US to buy corn and other agricultural products directly from more affluent African regions. Instead, farmers in the US Midwest are subsidized, which not only robs African farmers of their home market but also undermines the global market price. The situation might improve as the US 2007 Farm Bill may allow the use of up to $25 \%$ of emergency funds to purchase products in the region affected. However, huge ongoing agricultural subsidies in America and Europe continue to devastate local agricultural markets in Africa, whereas African farmers receive almost no aid.

In the long term, only an improved infrastructure can provide a solution to poverty on the African continent. One successful initiative is the 'Millennium Villages' project organized by the Earth Institute at Columbia University in partnership with the United Nations and others, where a sustainable local infrastructure including such as drinking wells, schools, fertilizers and essential medical care is provided to reduce famine and illness so that villagers can start to help themselves ${ }^{1}$.

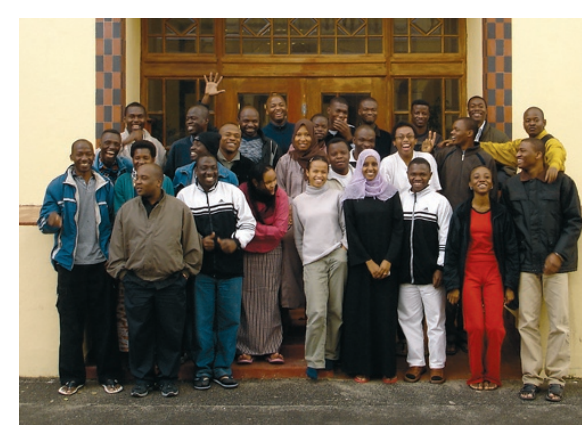

Students of the AIMS.

Obviously, such measures can only be a first step to reducing poverty. Simultaneously, it is crucial to improve education. In many African countries science teaching rarely exists on a satisfactory level. And this is where scientists can make a difference.

In their Commentary, Jeroen van den Brink and Izak Snyman describe the African Institute for Mathematical Sciences $^{2}$ (AIMS). At AIMS, gifted graduate students from all over Africa are taught advanced mathematical concepts that can then be used for applications including fundamental physics, materials science, bioinformatics and financial mathematics. Teachers are renowned scientists from all over the world, and the institute welcomes suggestions for potential courses. As van den Brink and Snyman summarize from their own experiences as teachers at AIMS, the students are highly motivated and progress is enormous, which has made it one of the most rewarding teaching experiences of their lives.

Obviously, teaching mathematics is less expensive than physics or engineering laboratory courses. Nevertheless, the example of AIMS suggests that even for such courses costs would remain significantly lower than in more developed regions. Therefore, the success of AIMS should encourage the creation of similar institutions. Conferences based in Africa may serve as a first nucleation point, where contacts with local scientists can be initiated. An example is the 'International Conference of MRS-Africa', where issues such as materials for energy and for water treatment are covered ${ }^{3}$. Similarly, the US-Africa Materials Institute at Princeton University facilitates the exchange of scientists between Africa and the US, but also addresses materials issues for improving the infrastructure in Africa ${ }^{4}$.

Scientists tend to think that the most they can do to solve the problems in impoverished regions is to stay in the lab or at the desk and to come up with scientific answers. This, however, is only part of the solution. Local problems are best solved locally, and for this scientific education at the highest level needs to be enhanced. As van den Brink and Snyman write, we need to teach the teachers.

Even for the most busy and most active scientists amongst our readers, pro bono teaching for three weeks at an African institution is an opportunity not to be missed. So why not consider doing this yourself and advance science where it is needed most?

\section{Published online: 21 0ctober 2007}

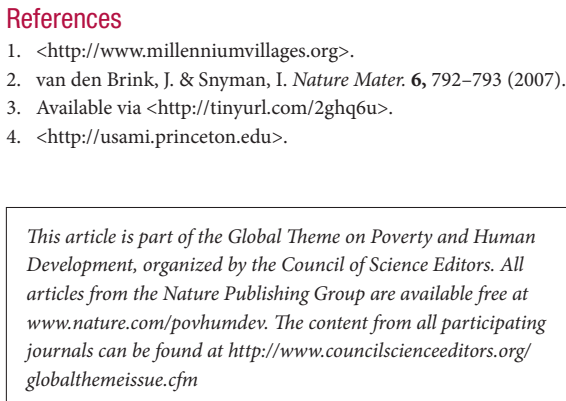

This article is part of the Global Theme on Poverty and Human Development, organized by the Council of Science Editors. All articles from the Nature Publishing Group are available free at www.nature.com/povhumdev. The content from all participating journals can be found at http://www.councilscienceeditors.org/ globalthemeissue.cfm 